\begin{tabular}{|c|l|}
\hline Title & $\begin{array}{l}\text { Photoelectrochemical Reduction of Carbon Dioxide at Si(111) Electrode Modified by Viologen Molecular Layer with } \\
\text { Metal Complex }\end{array}$ \\
\hline Author(s) & Sun, Yu; Masuda, Takuya; Uosaki, Kohei \\
\hline Citation & $\begin{array}{l}\text { Chemistry Letters, 41(3), 328 330 } \\
\text { https://doi.org/10.1246/1.2012.328 }\end{array}$ \\
\hline Issue Date & 2012-03 \\
\hline Doc URL & http://hdl.handle.net/2115/52105 \\
\hline Type & article(author version) \\
\hline File Information & CL41-3_328-330.pdf \\
\hline
\end{tabular}

Instructions for use 


\title{
Photoelectrochemical Reduction of Carbon Dioxide at Si(111) Electrode Modified by Viologen Molecular Layer with Metal Complex
}

\author{
Yu Sun, ${ }^{1}$ Takuya Masuda, ${ }^{2}$ and Kohei Uosaki*1,2,3 \\ ${ }^{1}$ Division of Chemistry, Graduate School of Science, Hokkaido University, Sapporo 060-0810 \\ ${ }^{2}$ Global Research Center for Environment and Energy based on Nanomaterials Science (GREEN), National Institute for Materials \\ Science (NIMS), Tsukuba 305-0044 \\ ${ }^{3}$ International Center for Materials Nanoarchitectonics (MANA), National Institute for Materials Science (NIMS), Tsukuba 305-0044
}

(Received <Month><Date>, <Year $>$; CL-<No >; E-mail: <insert corresponding e-mail address $>$ )

Photoelectrochemical carbon dioxide reduction was carried out at a p-type $\mathrm{Si}(111)$ electrode modified with a viologen molecular layer and $\mathrm{AuCl}_{4}{ }^{2-}$ or $\mathrm{PdCl}_{4}{ }^{2-}$. It was proved that the reduction reaction was mediated by viologen moiety and while $\mathrm{CO}_{2}$ reduction was dominant at the $\mathrm{Si}(111)$ electrode modified with $\mathrm{PdCl}_{4}{ }^{2-}$ in the potential region where viologen moiety was in the first reduced state, it became dominant at the electrode modified with $\mathrm{AuCl}_{4}{ }^{2-}$ when viologen moiety became the second reduced state. FT-IR measurement confirmed the formation of formic acid/formate ion at the $\mathrm{PdCl}_{4}{ }^{2-} /$ viologen-modified Si electrode.

Carbon dioxide fixation attracts much interest of many scientists and engineers not only because $\mathrm{CO}_{2}$ is considered to be one of the main causes of global warming ${ }^{1}$ but also because it is scientifically very challenging to convert $\mathrm{CO}_{2}$, one of the most stable molecules, to fuels and useful chemicals. $^{2}$ Electrochemical reduction of $\mathrm{CO}_{2}$ is one of the most studied systems, ${ }^{2-4}$ but very large overpotential and low current efficiency prevent its practical use. Moreover, if electricity is generated by using fossil fuel, more $\mathrm{CO}_{2}$ is produced. Photoelectrochemical and photocatalytic reduction of $\mathrm{CO}_{2}$ using semiconductor is ideal as solar energy can be utilized to reduce $\mathrm{CO}_{2}{ }^{2}$ Unfortunately, however, most of the semiconductors, which have a suitable bandgap for solar energy conversion, are corrosive in aqueous solutions. ${ }^{5}$ Furthermore, most of the semiconductor surfaces are not catalytically active for multi-electron transfer reactions such as hydrogen evolution and $\mathrm{CO}_{2}$ reduction, because they do not adsorb reaction intermediates with suitable strength. ${ }^{6-8}$ One of the methods to solve these problems is to modify the semiconductor surface with metal or metal ions, which act as catalyst. But this approach has one severe problem that surface states, which act as charge recombination centers, are often introduced at the metal-semiconductor interface as a result of the surface modification by metal. ${ }^{9}$

Several groups used organic molecular layers to separate catalytic metals and semiconductor surfaces so that the introduction of surface states, which is the result of direct contact between catalytic metals and semiconductor surface, can be avoided and demonstrated that efficiencies of photoelectrochemical reactions are significantly enhanced, although the position and amount of catalyst are not well controlled. $^{10,11}$ Recently, we have demonstrated that very efficient photoelectrochemical hydrogen evolution reaction (HER) can be achieved at a $\mathrm{Si}(111)$ electrode modified with a highly ordered organic molecular layer with viologen moieties, which is directly bonded to $\mathrm{Si}$ surface via $\mathrm{Si}-\mathrm{C}$ bond, as an electron mediator and Pt complex, which is confined within the molecular layer as a catalyst. ${ }^{12,13}$

In this paper, we have extended this approach to photoelectrochemical carbon dioxide reduction at p-type $\mathrm{Si}(111)$ electrode modified with viologen molecular layer and various metal complexes. $\mathrm{AuCl}_{4}{ }^{-}$and $\mathrm{PdCl}_{4}{ }^{2-}$ are chosen as complexes as electrochemical $\mathrm{CO}_{2}$ reduction is known to proceed efficiently at $\mathrm{Au}$ and $\mathrm{Pd}$ electrodes while $\mathrm{H}_{2}$ generation is dominant at $\mathrm{Pt}$ electrode in $\mathrm{CO}_{2}$ saturated solution. $^{14}$

Surface modification was carried out as schematically shown in Scheme 1. Details of the procedure for the modification by organic layers and characterization of modified surfaces have been reported before. ${ }^{12}$ Briefly, a freshly prepared hydrogen-terminated (H-) Si(111) surface $^{15}$ was sequentially treated to yield a viologen monolayermodified $\left(\mathrm{V}^{++}-\right) \mathrm{Si}(111)$ substrate: (1) $\mathrm{H}-\mathrm{Si}(111)$ surface was illuminated with $254 \mathrm{~nm}$ light for $2 \mathrm{~h}$ in deaerated 4vinylbenzylchloride to yield a 4-ethylbenzylchloride-modified (EBC-) Si(111) surface, (2) the substrate was then kept in benzene solution saturated with 4, 4'-bipyridine and then in 1bromobutane, both at $70^{\circ} \mathrm{C}$ for $12 \mathrm{~h}$ to obtain a $\mathrm{V}^{++}-\mathrm{Si}(111)$ surface. The $\mathrm{V}^{++}-\mathrm{Si}(111)$ was immersed in an aqueous solution containing $10 \mathrm{mM}$ of $\mathrm{NaAuCl}_{4}$ or $\mathrm{K}_{2} \mathrm{PdCl}_{4}$ for 20 min at room temperature to yield $\mathrm{Au}-$ and $\mathrm{Pd}-\mathrm{V}^{++}-\mathrm{Si}(111)$ surfaces, respectively.

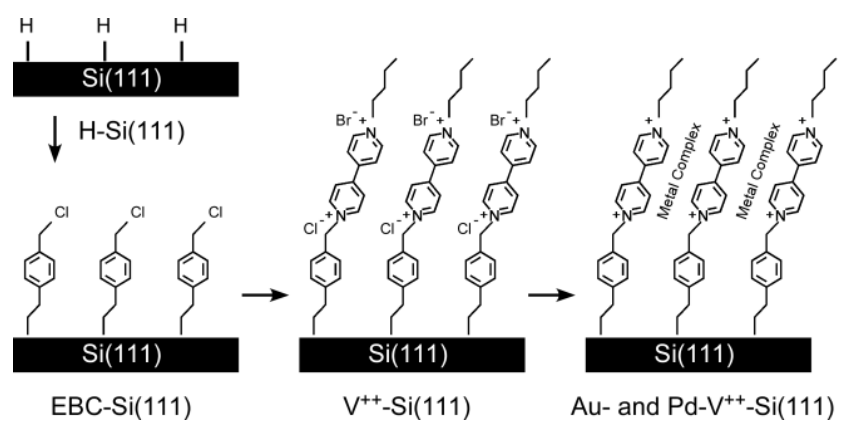

Scheme 1. Schematic illustration of the modification steps of hydrogen terminated (H-) $\mathrm{Si}(111)$ surface to obtain $\mathrm{Au}-$ and $\mathrm{Pd}-\mathrm{V}^{++}-\mathrm{Si}(111)$ surfaces. Metal Complex: $\mathrm{AuCl}_{4}{ }^{-}$and $\mathrm{PdCl}_{4}{ }^{2-}$. See the text for the detail. $^{12}$

X-ray photoelectron spectra (XP spectra) obtained using a Rigaku model XPS-7000 with monochromic $\mathrm{Mg} \mathrm{K} \alpha$ for the (A) $\mathrm{Au}-$ and (B) $\mathrm{Pd}-\mathrm{V}^{++}-\mathrm{Si}(111)$ surfaces in $\mathrm{Au} 4 \mathrm{f}$ and $\mathrm{Pd} 3 \mathrm{~d}$ regions, respectively, confirm the incorporation of the metals. ${ }^{16}$ 
Figure 1 shows I-V curves of the (A) Au- and (B) $\mathrm{Pd}-$ $\mathrm{V}^{++}$-Si(111) electrodes in $\mathrm{Ar}$ and $\mathrm{CO}_{2}$ saturated $0.1 \mathrm{M} \mathrm{Na}_{2} \mathrm{SO}_{4}$ aqueous solutions. The $\mathrm{pH}$ of the $\mathrm{Ar}$ saturated $0.1 \mathrm{M} \mathrm{Na}_{2} \mathrm{SO}_{4}$ solution was adjusted to 4.4 by adding $\mathrm{H}_{2} \mathrm{SO}_{4}$, since the $\mathrm{pH}$ of $0.1 \mathrm{M} \mathrm{Na}_{2} \mathrm{SO}_{4}$ changed from 5.9 to 4.4 by $\mathrm{CO}_{2}$ saturation. Relatively small current flowed at the n-Si(111) electrodes modified with viologen layer/metal complexes in dark both in Ar and $\mathrm{CO}_{2}$ saturated solutions. However, currents in $\mathrm{CO}_{2}$ saturated solution were clearly larger than those in $\mathrm{Ar}$ saturated solution at potentials more negative than ca. $-0.5 \mathrm{~V}$.
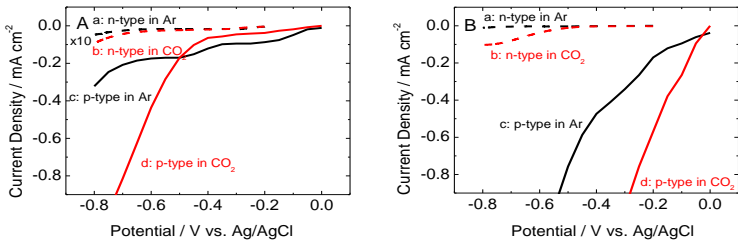

Figure 1.

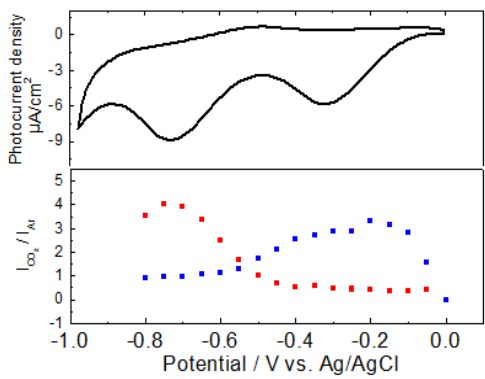

voltage

Currentrelations of

(A) $\mathrm{Au}-$ and (B) $\mathrm{Pd}-\mathrm{V}^{++}-\mathrm{Si}(111)$ electrodes in $0.1 \mathrm{M} \mathrm{Na}_{2} \mathrm{SO}_{4}$ aqueous solutions saturated with $\mathrm{Ar}$ (black; a, c) and $\mathrm{CO}_{2}$ (red; b, d) in dark (ntype, broken line; a, b) and under illumination (p-type, solid line; c, d) with a light intensity of $0.12 \mathrm{~mW} / \mathrm{cm}^{-2}$. Scan rate: $1 \mathrm{mV} / \mathrm{s}$. (C) Top panel: Cyclic voltammogram of p-type $\mathrm{V}^{++}-\mathrm{Si}(111)$ electrodes in a $0.1 \mathrm{M}$ $\mathrm{Na}_{2} \mathrm{SO}_{4}$ aqueous solution saturated with $\mathrm{Ar}$ under illumination with a light intensity of $0.12 \mathrm{~mW} / \mathrm{cm}^{-2}$. Scan rate: $100 \mathrm{mV} / \mathrm{s}$. Bottom panel: Ratio between currents at $\mathrm{Au}$ - (red) and $\mathrm{Pd}-\mathrm{V}^{++}-\mathrm{Si}(111)$ electrodes (blue) in $\mathrm{CO}_{2}$ saturated solution and that in $\mathrm{Ar}$ saturated solution $\left(\mathrm{I}_{\mathrm{CO}_{2}} / \mathrm{I}_{\mathrm{Ar}}\right)$ as a function of potential.

Cathodic currents in both the $\mathrm{Ar}$ and $\mathrm{CO}_{2}$ saturated solutions started to flow at much more positive potentials at the $\mathrm{p}$-Si(111) electrodes modified with viologen layer/metal complexes under illumination ${ }^{17}$ than those at the modified nSi(111) electrode in dark, although only negligibly small currents flowed in $\operatorname{dark}(<5 \mu \mathrm{A}$ at $-0.8 \mathrm{~V})$ as expected because electron is the minority carrier of p-type semiconductor. At the p-type $\mathrm{Pd}-\mathrm{V}^{++}-\mathrm{Si}(111)$ electrode, photocurrent started to flow at potential as positive as $0 \mathrm{~V}$ and increased significantly as potential became more negative both in the $\mathrm{Ar}$ and $\mathrm{CO}_{2}$ saturated solutions. Photocurrent in the $\mathrm{CO}_{2}$ saturated solution was larger than that in the Ar saturated solution in the potential region shown in Fig. 1 but both became almost the same as potential became more negative than ca. $-0.6 \mathrm{~V}$. On the other hand, although photocurrent started to flow also at around $0 \mathrm{~V}$ at the $\mathrm{Au}-\mathrm{V}^{++}$p-Si(111) electrode in both solutions, it did not increase much even when potential was made more negative, particularly in the Ar saturated solution. Photocurrent in the $\mathrm{CO}_{2}$ saturated solution significantly increased and became larger than that in the Ar saturated solution when potential became more negative than ca. $-0.55 \mathrm{~V}$.
These trends are more clearly seen in the bottom panel of Fig. 1(C), which shows potential dependencies of the ratio between photocurrents in the $\mathrm{CO}_{2}\left(\mathrm{I}_{\mathrm{CO}_{2}}\right)$ and $\mathrm{Ar}$ saturated solutions $\left(\mathrm{I}_{\mathrm{Ar}}\right)$ at the $\mathrm{Au}-\mathrm{V}^{++}$- and $\mathrm{Pd}-\mathrm{V}^{++}-\mathrm{Si}(111)$ electrodes. At the Pd modified Si electrode, $\mathrm{I}_{\mathrm{CO}_{2}}$ became larger than $\mathrm{I}_{\mathrm{Ar}}$ as soon as photocurrent started to flow at $0 \mathrm{~V}$ but $\mathrm{I}_{\mathrm{CO}_{2}} / \mathrm{I}_{\mathrm{Ar}}$ gradually decreased as potential became more negative than ca. $-0.2 \mathrm{~V}$ and became 1 as potential became more negative than ca. $-0.6 \mathrm{~V}$ as mentioned before. At the Au modified $\mathrm{Si}$ electrode, $\mathrm{I}_{\mathrm{CO}_{2}}$ was smaller than $\mathrm{I}_{\mathrm{Ar}}$ in the relatively positive potential region but $\mathrm{I}_{\mathrm{CO} 2} / \mathrm{I}_{\mathrm{Ar}}$ increased significantly as potential became more negative than ca. $-0.5 \mathrm{~V}$ and reached 4 at $-0.7 \mathrm{~V}$. The top panel of Fig. 1(C) is the Cyclic voltammogram (CV) of $\mathrm{V}^{++}-\mathrm{Si}(111)$ electrode without metal complex under illumination obtained with very fast scan rate $(50 \mathrm{mV} / \mathrm{s})$. Reduction peaks of viologen moiety are clearly observed at $0.25 \mathrm{~V}$ and $-0.7 \mathrm{~V}$ for the reduction of $\mathrm{V}^{++}$to $\mathrm{V}^{+\cdot}$ and of $\mathrm{V}^{+\cdot}$ to $\mathrm{V}^{*}$, respectively. Positions of these peaks were more positive than those observed at n-type $\mathrm{V}^{++}-\mathrm{Si}(111)$ electrode in dark as expected. $^{12(\mathrm{~b})}$ Potential dependencies of photocurrent and $\mathrm{I}_{\mathrm{CO} 2} / \mathrm{I}_{\mathrm{Ar}}$ seem to be related to the reduced state of viologen moiety. While at the $\mathrm{Pd}-\mathrm{V}^{++}-\mathrm{Si}(111)$ electrode, large photocurrent flowed in both $\mathrm{Ar}$ and $\mathrm{CO}_{2}$ saturated solution as soon as the reduction of $\mathrm{V}^{++}$to $\mathrm{V}^{+}$started, at the $\mathrm{Au}-\mathrm{V}^{++}$$\mathrm{Si}(111)$ electrode, only relatively small and almost no photocurrent were observed in $\mathrm{Ar}$ and $\mathrm{CO}_{2}$ saturated solutions respectively, in potential region where viologen moiety was in $\mathrm{V}^{+}$and significant increase of photocurrent was observed in $\mathrm{CO}_{2}$ saturated solution as soon as $\mathrm{V}^{+}$was reduced to $\mathrm{V}^{*}$. This difference should be due to the difference in the energy to form adsorbed intermediate states on the metal catalysts.

As a qualitative analysis of the products of $\mathrm{CO}_{2}$ reduction, in situ FT-IR measurements were performed at the $\mathrm{Au}-$ and $\mathrm{Pd}-\mathrm{V}^{++}-\mathrm{Si}(111)$ electrodes in $0.1 \mathrm{M} \mathrm{Na}_{2} \mathrm{SO}_{4}$ solution saturated with $\mathrm{CO}_{2}{ }^{18}$ Figure 2(A) shows IR spectra (spolarization) obtained at the $\mathrm{Pd}-\mathrm{V}^{++}-\mathrm{Si}(111)$ in the $\mathrm{CO}_{2}$ saturated $0.1 \mathrm{M} \mathrm{Na}_{2} \mathrm{SO}_{4}$ solution keeping the potential at -0.7 $\mathrm{V}$ for a given period of time under illumination with a spectrum measured in dark before illumination as a reference.
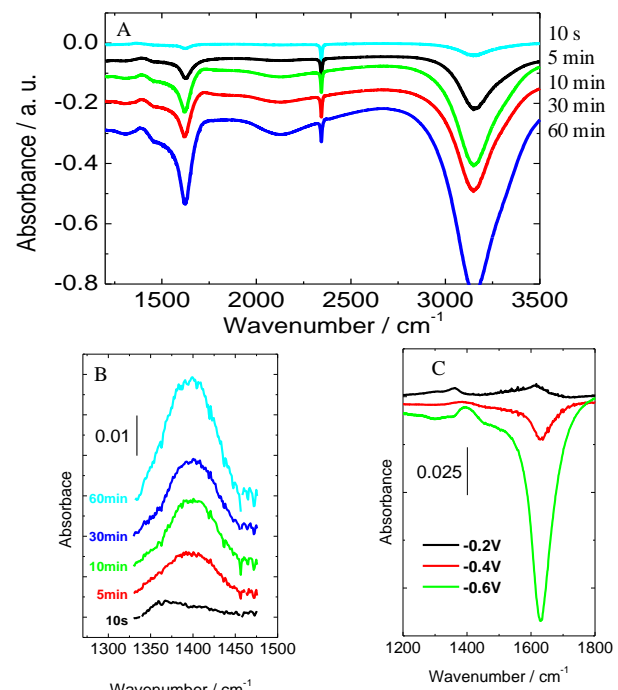

Figure 2. IR spectra at the $\mathrm{Pd}-\mathrm{V}^{++}-\mathrm{Si}(111)$ electrode in a $\mathrm{CO}_{2}$ saturated $0.1 \mathrm{M} \mathrm{Na}_{2} \mathrm{SO}_{4}$ solution $(\mathrm{A}, \mathrm{B})$ with keeping the potential at $-0.7 \mathrm{~V}$ for a given period of time under illumination in (A) $1250-3500 \mathrm{~cm}^{-1}$ and (B) 
3 $1325-1475 \mathrm{~cm}^{-1}$ regions with background correction, and (C) at various potentials in $1200-1800 \mathrm{~cm}^{-1}$ region.

No significant difference was noticed between the $\mathrm{p}$ - and s-polarized spectra. ${ }^{20}$ Negative going peaks due to the consumption in the thin layer were observed at around 1600 , 2350 , and $3,200 \mathrm{~cm}^{-1}$, corresponding to bending of $\mathrm{OH}$ of water, $\mathrm{CO}$ stretching of dissolved $\mathrm{CO}_{2}$, and $\mathrm{OH}$ stretching of water, respectively, showing that $\mathrm{HER}$ and $\mathrm{CO}_{2}$ reduction proceeded. A small positive going peak due to the accumulation of reduction product was observed at around $1,410 \mathrm{~cm}^{-1}$, which corresponds to symmetric stretch of carboxylate group. The growth of this peak with time is more clearly seen in Fig. 2 (B), which shows IR spectra in 1325$1475 \mathrm{~cm}^{-1}$ region with correction of background due to strong negative going $\mathrm{OH}$ bending peak. This agrees with previous reports that the main product of electrochemical carbon dioxide reduction reaction at $\mathrm{Pd}$ electrode is formic acid/formate ion. ${ }^{21}$ Asymmetric stretching peak of carboxylate group, which should be present at around $1,510 \mathrm{~cm}^{-1}$ is not visible because of strong negative going $\mathrm{OH}$ bending peak at this potential. IR spectra obtained various potentials shown in Fig. 2(C) indicate that at $-0.2 \mathrm{~V}$, the negative going $\mathrm{OH}$ bending peak is not visible and small positive going peaks due to symmetric and symmetric stretch of carboxylate group are observed. This is in good agreement with the result shown in Fig. 1(B) that dominant reaction at this potential is $\mathrm{CO}_{2}$ reduction.

In situ FT-IR measurements obtained at the $\mathrm{Au}-\mathrm{V}^{++}$$\mathrm{Si}(111)$ electrode in $0.1 \mathrm{M} \mathrm{Na}_{2} \mathrm{SO}_{4}$ solution saturated with $\mathrm{CO}_{2}$ shows only negative going peaks due to the consumption in the thin layer at around 1600,2350 , and $3,200 \mathrm{~cm}^{-1}$, corresponding to bending of $\mathrm{OH}$ of water, $\mathrm{CO}$ stretching of dissolved $\mathrm{CO}_{2}$, and $\mathrm{OH}$ stretching of water, respectively, and no positive going peeks were observed. Thus, although it is confirmed that HER and $\mathrm{CO}_{2}$ reduction proceeded at the Au$\mathrm{V}^{++}$-Si(111) electrode, no product was determined. According to previous reports, main product of $\mathrm{CO}_{2}$ reduction at gold electrode is CO. ${ }^{14}$

In conclusion, photoelectrochemical carbon dioxide reduction was significantly enhanced by modifying $\mathrm{Si}(111)$ surfaces by the organic molecular layer with viologen moieties and $\mathrm{AuCl}_{4}^{2-}$ or $\mathrm{PdCl}_{4}{ }^{2-}$. It was confirmed that viologen moiety plays an important role for mediating electron transfer from $\mathrm{Si}$ to metal catalysts. While $\mathrm{CO}_{2}$ reduction was dominant at the $\mathrm{Si}(111)$ electrode modified with $\mathrm{PdCl}_{4}^{2-}$ in the potential region where viologen moiety was in the first reduced state, the second reduced state is required to reduce $\mathrm{CO}_{2}$ at the electrode modified with $\mathrm{AuCl}_{4}{ }^{2-}$. FTIR measurements confirmed the formation of formic acid/formate ion as a product of $\mathrm{CO}_{2}$ reduction and selectivity of $\mathrm{CO}_{2}$ reduction to HER is high at the positive potential at $\mathrm{Pd}-\mathrm{V}^{++}-\mathrm{Si}(111)$ electrode. The decrease of selectivity for $\mathrm{CO}_{2}$ reduction at the $\mathrm{Pd}-\mathrm{V}^{++}-\mathrm{Si}(111)$ electrode as potential became negative should simply be due to the low surface concentration of $\mathrm{CO}_{2}$ with respect $\mathrm{H}_{2} \mathrm{O}\left(\mathrm{H}^{+}\right)$for $\mathrm{HER}$. More detailed analysis including gaseous products is under way.

Professors Katsuaki Shimazu and Toshikazu Kawaguchi are acknowledged for XPS measurements. The present work was partially supported by GCOE Program (Project No. B01: Catalysis as the Basis for Innovation in Materials Science), World Premier International Research Center (WPI) Initiative on Materials Nanoarchitectonics, and MEXT Program for Development of Environmental Technology using Nanotechnology from Ministry of Education, Culture, Sports, Science and Technology, Japan. YS is supported by MEXT scholarship for foreign students.

\section{References and Notes}

1 J. O'M. Bockris, in Energy Options, Halsted, New York, 1980.

2 M. M. Halmann, in Chemical Fixation of Carbon Dioxide-Methods for Recycling $\mathrm{CO}_{2}$ into Useful Products, CRC, Florida, 1993, Chap. 8, pp. 121-127.

3 M. Mikkelsen, M. Jorgensen, F. C. Kreds, Energy Environ. Sci. 2010, 3, 43.

4 Y. Hori, in Modern Aspects of Electrochemistry, ed. by C. G. Vayenas, R. White, M. Gamboa-aldeco, Springer, New York, 1999 Vol. 42, Chap. 3, pp. 89-189.

5 A. Nozik, Annu. Rev. Phys. Chem. 1978, 29, 189.

6 J. O'M. Bockris, K. Uosaki, J. Electrochem. Soc. 1977, 124, 1348.

7 K. Uosaki, H. Kita, in Modern Aspects of Electrochemistry, ed. by R. E. Write, J. O'M. Bockris, B. E. Conway, Springer, New York, 1986, Vol. 18, Chap. 3, pp. 1-60.

8 a) Y. Nakato, S. Tonomura, H. Tsubomura, Ber. Bunsenges, Phys. Chem. 1976, 80, 1289. b) W. Kautek, J. Gobrecht, H. Gerischer, Ber. Bunsenges, Phys. Chem. 1980, 84, 1034. c) A. Heller, Acc. Chem. Res. 1981, 14, 154. d) R. N. Dominey, N. S. Lewis, J. A. Bruce, D. C. Bookbinder, M. S. Wrighton, J. Am. Chem. Soc. 1982, 104, 467. e) F. R. E. Fan, R. G. Keli, A. J. Bard, J. Am. Chem. Soc. 1983, 105, 220. f) K. Uosaki, H. Kita, Chem. Lett. 1984, 13, 301. g) M. Szklarczyk. J. O'M. Bockris, J. Phys. Chem. 1984, 88, 5241.

9 a) Y. Nakato, K. Ueda, H. Yano, H. Tsubomura, J. Phys. Chem. 1988, 92, 2316. b) K. Uosaki, Y. Shigematsu, H. Kita, Chem. Lett. 1988, 11, 1815. c) K. Uosaki, Y. Shigematsu, S. Kaneko, H. Kita, J. Phys. Chem. 1989, 93, 6521 .

10 a) D. C. Bookbinder, J. A. Bruce, R. N. Dominey, N. S. Lewis, M. S. Wrighton, Proc. Natl. Acad. Sci. USA 1980, 11, 6280. b) R. N. Dominey, N. S. Lewis, J. A. Bruce, D. C. Bookbinder, M. S. Wrighton, J. Am. Chem. Soc. 1982, 104, 467.

11 a) K. Nakato, S. Takabayashi, A. Imanishi, K. Murakoshi, Y. Nakato, Sol. Energy Mat. Sol. C 2004, 83, 323. b) S. Takabayashi, M. Ohashi, K. Mashima, Y. Liu, S. Yamazaki, Y. Nakato, Langmuir 2005, 21, 8832 .

12 a) T. Masuda, K. Uosaki, Chem. Lett. 2004, 33, 788. b) T. Masuda, K. Shimazu, K. Uosaki, J. Phys. Chem. C 2008, 112, 10923.

13 T. Masuda, H. Fukumitsu, S. Takakusagi, W. J. Chun, T. Kondo, K. Asakura, K. Uosaki, Adv. Mater. 2012, 24, 268.

14 a) Y. Hori, H. Wakebe, T. Tsukamo, O. Koga, Electrochimica Acta.1994, 39, 1833. b) M. Azuma, K. Hashimoto, M. Hiramot, J. Electrochem. Soc., 1990, 137, 1772.

15 S. Ye, T. Ichihara, K. Uosaki, Appl. Phys. Lett. 1999, 75, 1562.

16 G. E. Muilenberg, in Handbook of X-Ray Photoelectron Spectroscopy, Perkin-Elmer, Minnesota, 1978.

17 Illumination was provided by a $500 \mathrm{~W}$ xenon lamp (Ushio, UXL500-D) through an IR cut filter (Toshiba, IRA-20), a UV cut filter (Sigma Koki) and an ND filter (Toshiba).

18 ATR FT-IR spectra were obtained in thin layer configuration ${ }^{19}$ using a Bio-Rad FTS-30 spectrometer equipped with a mercury cadmium telluride ( $\mathrm{HgCdTe})$ detector cooled with liquid nitrogen. A diode laser $\left(13 \mathrm{~mW} \mathrm{~cm}^{-2}\right)$ was used as a light source. All the spectra were measured by integrating 32 interferrograms with a resolution of $2 \mathrm{~cm}^{-1}$.

19 K. Uosaki, Y. Shigematsu, H. Kita, K. Kunimatsu, J. Phys. Chem., 94, 11, 4623-4627 (1990).

20 It must be noted the non-zero contribution of surface species in spolarized IR spectra at semiconductor electrode, although spolarized IR spectra at metal electrode contains no information from the surface species. ${ }^{19}$

21 a) K. Ohkawa, K. Hashimoto, A. Fujishima, J. Electroanal. Chem. 1993, 345, 445. b) K. Ohkawa, Y. Noguchi, S. Nakayama, K. Hashimoto, A. Fujishima, J. Electroanal. Chem. 1994, 369, 
Chemistry Letters Vol. 3*, No. * (200*)

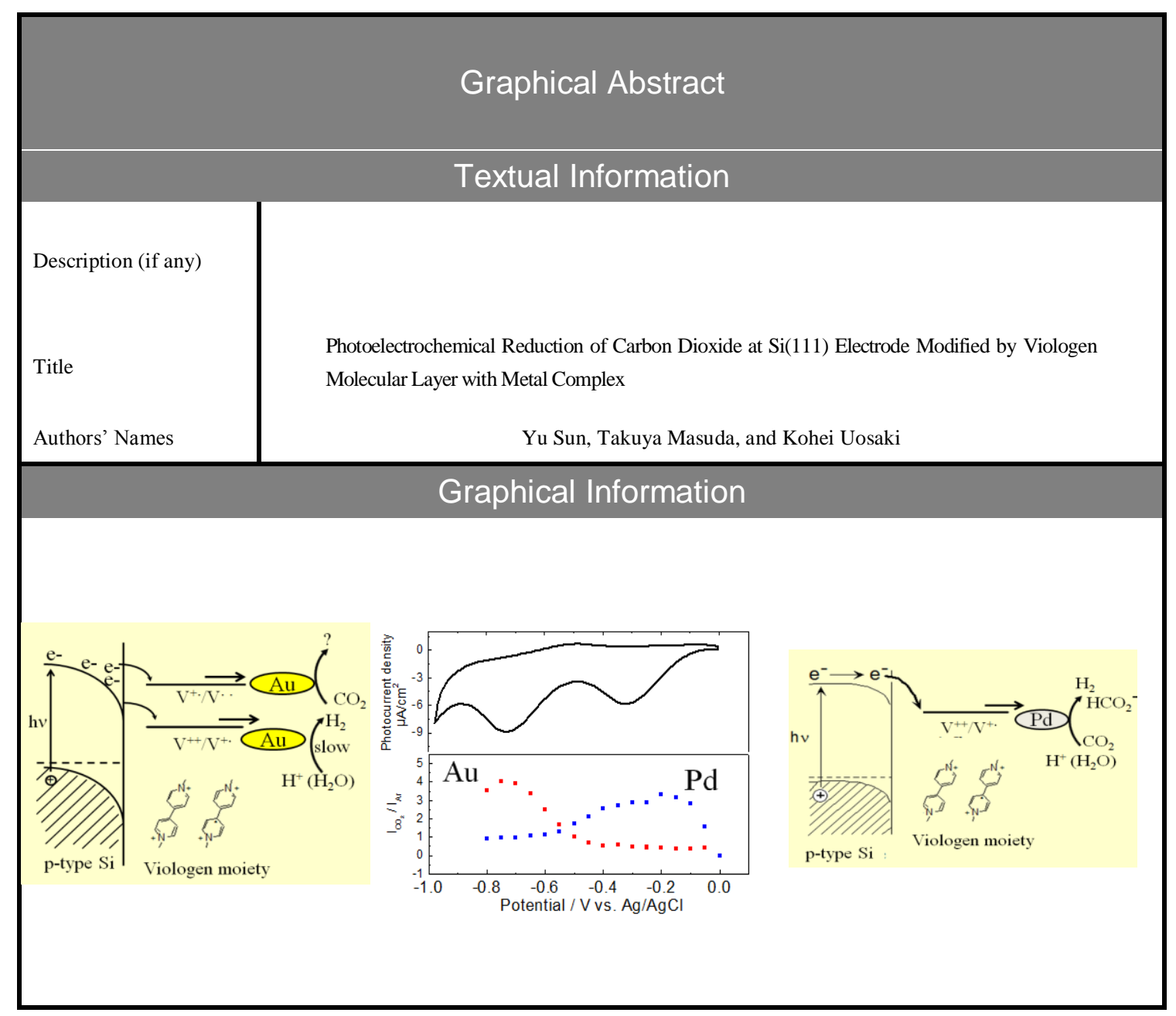

